\title{
1 Juvenile Hormone manipulation affects female reproductive status and 2 aggressiveness in a non-social parasitoid wasp
}

3

4 Anthony G.E. Mathiron ${ }^{1}$, Ryan L. Earley ${ }^{2}$ and Marlène Goubault ${ }^{1}$

Tours, France 35487, United States

\section{Author for correspondence:}

Anthony Mathiron

Telephone number: +330247367355

e-mail: anthony.mathiron@sfr.fr

${ }^{1}$ Institut de Recherche sur la Biologie de l'Insecte, UMR 7261 CNRS - Université de Tours, Parc Grandmont, 37200

${ }^{2}$ Department of Biological Sciences, The University of Alabama, 300 Hackberry Lane, Box 870344, Tuscaloosa, AL

Abstract. In vertebrates, titers of androgens such as testosterone are known to upregulate aggressive behaviors associated with reproduction. In insects, juvenile hormone ( $\mathrm{JH})$ is a good candidate for studying the flexibility of insect endocrine responses because it has important effects on both reproductive processes and behavior. JH has a gonadotropic effect across a broad range of insect species, increasing ovarian development in females, and may have a role in the regulation of aggressive behavior during competition. In Hymenoptera, the functions of JH have been studied in facultatively eusocial species such as polistine wasps, bumblebees, ants and bees. Surprisingly, no work has yet focused on the relationship between $\mathrm{JH}$, reproduction and aggressiveness in a nonsocial Hymenoptera, although it may help to understand how JH actions have evolved across taxa with different degrees of sociality. Here, we explored how JH treatment influenced: i) female reproductive status, and ii) the intensity (aggressiveness) and resolution of conflict, in Eupelmus vuilleti (Hymenoptera: Eupelmidae), a solitary ectoparasitoid wasp in which females fight over hosts. 
26 We demonstrated that intra-abdominal injections of $\mathrm{JH}$ increased the number of mature eggs in

27 females after $24 \mathrm{~h}$. In addition, the number of aggressive behaviors displayed by females was affected

by the interaction between $\mathrm{JH}$ treatment and the number of mature eggs in their abdomen, but mature

egg load alone predicted the outcome of staged contests. Wasps were more aggressive when they had more ready-to-lay eggs, with this effect being stronger when females were injected with $\mathrm{JH}$.

31 Moreover, females won more frequently when they had higher mature egg load. Our results highlight how $\mathrm{JH}$ affects egg maturation and aggressive behaviors in Eupelmus vuilleti females. To our knowledge, this is the first study showing that hormone manipulation can modulate females' reproduction status and behavior during intraspecific competition over hosts in a non-social hymenopteran parasitoid.

Keywords: juvenile hormone, reproductive maturation, aggressive behaviors, conflict resolution

invertebrate animals commonly exhibit aggressive behaviors during conflicts over such resources (Collias, 1944; Breed and Bell, 1983; Briffa and Hardy, 2013). For example, in parasitoid insects, hosts represent an indivisible resource over which females compete to lay their eggs, and physical interactions between females for host access have been observed in various parasitoid species (Hughes et al., 1994; Petersen and Hardy, 1996; Field and Calbert, 1999; Goubault et al., 2007; Mohamad et al., 2010, Mathiron et al., 2018). In many animal taxa, aggressive conflicts have also been observed between individuals for sexual partners (West-Eberhard, 1979; Schwagmeyer and Woontner, 1985; Simmons, 1986), food (Barton, 1993; Vogel, 2005), territories (Rowland, 1989; 48 Festa-Bianchet et al., 1990), and dominance status (Chase, 1974). However, being constantly aggressive can be costly, as potential physical injuries can lead to death (Palombit, 1993; Innocent et 
1999). Animals should therefore evaluate the costs and benefits of exhibiting agonistic behaviors and then behave appropriately (Maynard-Smith and Price, 1973). physiological responses to their current environment (Tibbetts and Crocker, 2014). In vertebrates, testosterone is generally involved in the modulation of aggressive behaviors during conflicts associated with reproduction, such as the establishment and maintenance of breeding territories, mate access, and offspring defense (Wingfield, 1984). For example, Salvador et al. (1996) showed that testosterone supplementation in large males of the territorial lizard Piammodromu algirus increased the number of chasing behaviors toward conspecific intruders. Moreover, during mate choice, female zebra finches treated with testosterone were more aggressive toward conspecific females than control individuals (Adkins-Regan, 1999). Whilst well- described in vertebrates, the endocrine basis of behavior is still relatively unknown in insects (Zera, 2007; Tibbetts et al., 2014). Because vertebrates and insects have similar behaviors but different endocrine systems (Nijhout, 1994; Adkins-Regan, 2005), exploring how hormones modulate insects behaviors can therefore provide insight into the evolution of endocrine regulation of behavior (Emlen and Nijhout, 2000). and behavior. Together with nutrition (see the review of Wheeler, 1996), JH plays an important and diverse role in reproduction in many adult insect species by regulating vitellogenesis in the fat body and vitellogenin uptake by the ovaries (reviewed by Tobe and Stay, 1985; Nijhout, 1994; Robinson and Vargo, 1997; Hartfelder, 2000). In Hymenoptera, JH is involved in the regulation of ovarian development in the facultatively eusocial sweat bee Megalopta genalis (Smith et al., 2013) and in primitively social species like polistine wasps (Barth et al., 1975), halictine bees (Bell, 1973) and bumblebees (Bloch et al., 2000; Amsalem et al., 2014). However, in the highly social honeybee Apis 
regulation of reproduction (reviewed in Robinson, 1992; Robinson and Vargo, 1997). In many eusocial hymenopterans, $\mathrm{JH}$ is also associated with displays of behaviors often judged to be aggressive (Tibbetts and Crocker, 2014). For example, in the epiponine wasp Polybia micans, JH may fuel aggressive behaviors of single queens heading a colony (Kelstrup et al. 2014a). Similar observations have been made in paper wasps, in which high $\mathrm{JH}$ titers are associated with dominance behaviors (Röseler et al., 1980, 1984; Giray et al., 2005; Tibbetts and Huang, 2010; Tibbetts et al., 2013; Kelstrup et al. 2016; but see Kelstrup et al., 2015). In honeybees, JH titers are higher in more aggressive workers and $\mathrm{JH}$ treatments cause honeybees to exhibit more frequent guarding behaviors (Sasagawa et al., 1989; Pearce et al., 2001). However, JH has no effect on aggression in the swarmfounding epiponine wasp Synoeca surinama (Kelstrup et al., 2014b) and may even be negatively correlated with aggression in the queenless ponerine ant, Streblognathus peetersi (Brent et al., 2006). aggressive behaviors towards conspecific competitors (Mohamad et al., 2010; Mathiron et al., 2018). Previous studies have investigated the role of different factors (e.g., egg load, host density and host 
101 Mathiron et al., 2018), but nothing is known about how hormones modulate aggressiveness during 102 competition for host access.

While measuring variation in hormone titers is an important first step to understand the endocrine basis of phenotypic plasticity (Zera, 2007), one method that allows for understanding individual responses to hormonal change is to administer a similar amount of hormone to numerous 106 individuals and, subsequently, to test how hormone manipulations affect the phenotype (Tibbetts and 107 Izzo, 2009). As such, manipulation of $\mathrm{JH}$ is one of the most common methods employed to understand its mode of action and functions in insects (Sláma, 1971; Ramaseshadri et al., 2012). A first experiment was therefore designed to determine if $\mathrm{JH}$ treatment affected female reproductive status. As for many other insect species, we expected JH to have a gonadotropic effect in females,

i.e. that wasps treated with $\mathrm{JH}$ would have more ready-to-lay eggs than control females (i.e. treated with vehicle). In a second experiment, we studied whether aggressiveness and resolution of conflicts between females were influenced by a $\mathrm{JH}$ treatment. We expected that individuals treated with $\mathrm{JH}$ would display more aggressive behaviors and would ultimately be more likely to win contests for 115 hosts relative to control females.

\section{2. Material and Methods}

\subsection{Laboratory breeding}

In 2007, E. vuilleti emerged from cowpea seeds collected in Togo (West Africa) and infested by the bruchid beetle Callosobruchus maculatus. Parasitoids were then bred in the laboratory (IRBI, 121 University of Tours, France) on larval and pupal stages of $C$. maculatus, according to the 122 methodology described by Jaloux et al. (2004). All experimental procedures were carried out in a 123 climate room at $30^{\circ} \mathrm{C}$ and $12: 12 \mathrm{~h}$ light: dark. Cowpea seeds were dissected to collect hosts for $E$. 124 vuilleti, which were then individually placed in a standard transparent gelatin capsule (length: $2 \mathrm{~cm}$, 125 diameter: $0.6 \mathrm{~cm}$ ). This system mimics a cowpea seed without significantly altering the oviposition 
behavior of females, and facilitates observation of the number of eggs laid by females (Gauthier and

127 Monge, 1999). Previous studies have shown that after a period of acclimation, parasitoid females behave in the same manner to the presence of hosts inside seeds and capsules (Gauthier and Monge, 1999; Jaloux et al., 2004), although the number of eggs laid on hosts is slightly lower inside capsules

130 (Damiens et al., 2001).

Females used in the following experiments emerged in isolation, which prevented them from having any previous experience of oviposition or competition. We placed them individually in petri dishes (diameter: $8.5 \mathrm{~cm}$; height: $2.7 \mathrm{~cm}$ ), and provided cotton soaked in water and one pupa of $C$. vuilleti is a synovigenic parasitoid species: emerging females possess a few mature eggs and they mature additional eggs throughout their adult life. Oviposition activity increases over time and peaks three days after emergence (Jaloux et al., 2004). To stimulate oogenesis (Terrasse and Rojas-Rousse, 1986), we also gave one male to females during the first day.

\subsection{Experiment 1: Effect of JH on females' reproductive status}

To investigate the influence of JH treatment on female reproductive status, two-day old wasps were randomly assigned to one of the five following treatments: they received either $0.04 \mu \mathrm{L}$ of acetone $(\mathrm{N}=36)$ or $0.04 \mu \mathrm{L}$ of JHIII (purchased from Sigma-Aldrich, Inc.) dissolved in acetone at four different concentrations $(8,16,32$ or $64 \mathrm{pg} / \mu \mathrm{l} ; \mathrm{N}=35, \mathrm{~N}=39, \mathrm{~N}=39, \mathrm{~N}=37$, respectively). The final volume was established based on preliminary tests showing that mean haemolymph volume in E. vuilleti females is $0.175 \mu \mathrm{l}$ (but this volume may vary depending on body mass, physiological state or environmental conditions; Borde et al., unpublished data). Immediately after being immobilized on a petri dish that was cooled by ice, wasps were injected into the abdomen through the intersegmental membrane using the nanoliter injector Nanoject III (Drummond Scientific Company). Females were then individually placed in a petri dish and were frozen at $-20^{\circ} \mathrm{C}$ either $4 \mathrm{~h}$ $(\mathrm{N}=20$ for injections of $0,8,16,32 \mathrm{pg} / \mu \mathrm{l}$ and $\mathrm{N}=18$ for injection of $64 \mathrm{pg} / \mu \mathrm{l})$ or $24 \mathrm{~h}(\mathrm{~N}=16$ for 
injection of $0 \mathrm{pg} / \mu \mathrm{l}, \mathrm{N}=15$ for injection of $8 \mathrm{pg} / \mu \mathrm{l}$, and $\mathrm{N}=19$ for injections of 16,32 and $64 \mathrm{pg} / \mu \mathrm{l})$

152 after injection. Females were deprived of hosts so that no mature eggs were laid during this period.

153 Finally, all females were weighed using an electronic balance (Ohaus Discovery ${ }^{\circledR}$ model, accuracy:

$1540.01 \mathrm{mg}$ ) and then dissected to count mature (i.e. ready-to-lay) oocytes in their abdomen.

156 2.3. Experiment 2: Effect of JH on females' aggressiveness and contests outcome

To investigate the influence of JH manipulation on female aggressive behavior, three-days old wasps were randomly assigned to two different injection treatments: females injected with either 159 $0.04 \mu \mathrm{L}$ of JHIII diluted in acetone (concentration $=32 \mathrm{pg} / \mu \mathrm{l}$ ) or $0.04 \mu \mathrm{L}$ of acetone alone. Wasps 160 were marked on the dorsal part of their thorax with a dot of bright yellow or bright red acrylic paint the day before behavioral observations to allow individual identification during contests. Paint color did not affect contest outcomes (wasps painted red won 17 of 25 contests; binomial test: $\mathrm{P}=0.11$ ). 163 Females were deprived of hosts for at least $2 \mathrm{~h}$ before the start of the contest so that they were more 164 ready to oviposit. At the beginning of the observation, two wasps were simultaneously introduced 165 into an apparatus consisting of a plastic block made of three chambers linked by a narrow channel (Petersen and Hardy, 1996; Fig. 1.). 


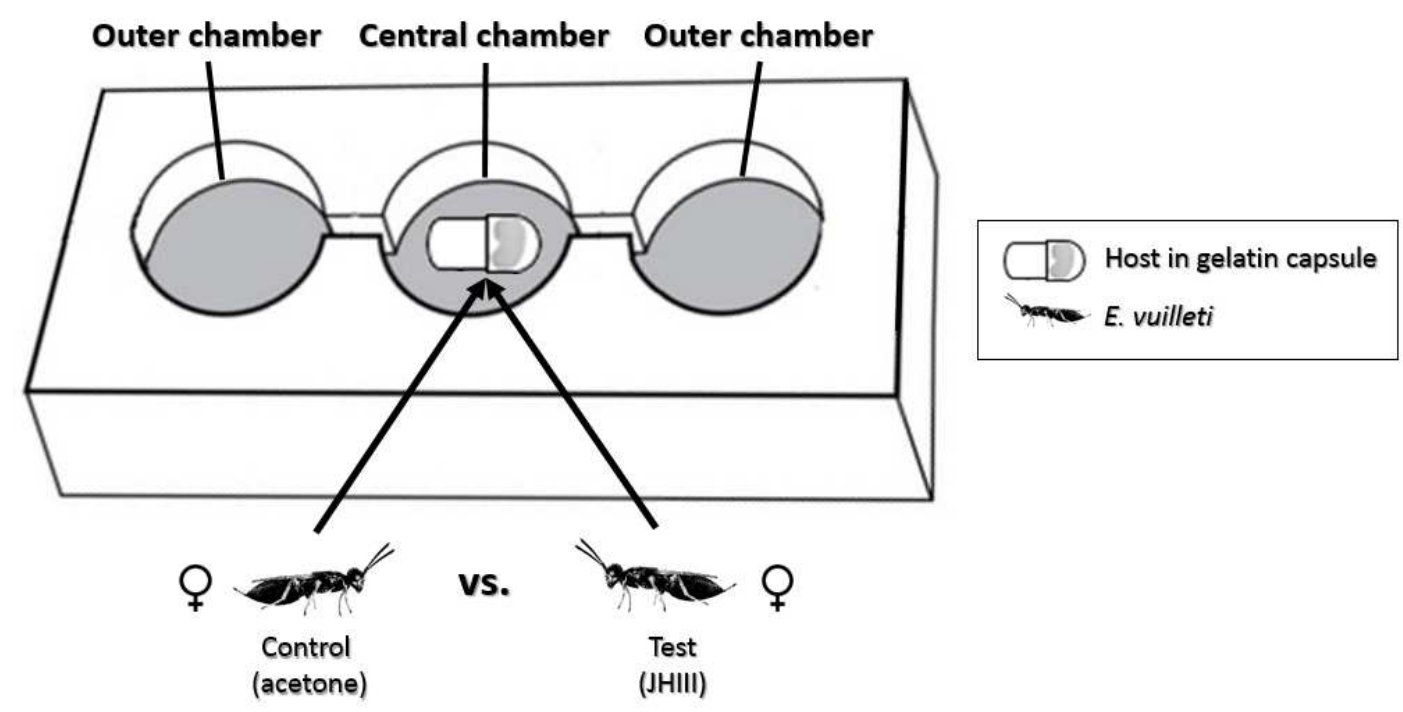

170 Figure 1: Experimental apparatus (adapted from Peterson \& Hardy, 1996). Three chambers $($ diameter $=1.8 \mathrm{~cm}$, depth $=$ $1710.6 \mathrm{~cm}$ ) linked by a narrow channel (width $=0.1 \mathrm{~cm}$ ) were made in a plastic block, decked with Plexiglas. At the start of 172 experiments, two E. vuilleti females (one control and one test female) were simultaneously introduced into the central 173 chamber already containing a $4^{\text {th }}$ instar larva of $C$. maculatus within a gelatin capsule mimicking a seed. Wasp behavior 174 was observed from above the contest arena.

All contests were run between one control female (i.e., injected with acetone only) and one 177 test female (i.e., injected with JHIII), challenging for a $4^{\text {th }}$ instar larva of $C$. maculatus located in 178 gelatin capsule and previously placed in the central chamber of the contest arena (Fig.1.). Mathiron 179 et al. (2018) showed that females with previous oviposition experience on pupae were more 180 motivated to gain access to a $4^{\text {th }}$ instar larva. Contests occurred between females of the same age (3 days old), marked with different colors and visually matched for size; post-experiment data analysis confirmed that contestants of the same dyad did not differ significantly in body mass (Wilcoxon signed-ranks test: $\mathrm{T}=147.5, \mathrm{~N}=25, \mathrm{P}=0.7)$. Both females could freely move throughout the entire contest arena. Observations lasted $1 \mathrm{~h}$ or were stopped when: i) one female pushed her opponent out of the central chamber, ii) one female exited the central chamber for at least 2 min, or iii) neither female touched the host nor displayed aggressive interactions for at least 2 min. 
During all tests, we recorded oviposition and aggressive behaviors displayed by each female.

188 Upon detection of a conspecific (females raised their antennae in the direction of their opponent), 189 females frequently interrupted their behavioral oviposition sequence (Mohamad et al., 2010). They 190 either simply kick their opponent with their legs without taking their ovipositor out of the capsule 191 (defensive behavior) or can escalate to a full attack, in which case one female generally chases her 192 opponent away from the capsule, hits her with her head or mounts her (Mathiron et al., 2018). 193 Chasing, hitting and mounting can lead to the loser leaving the central chamber of the arena $(8 / 25$ 194 loser females left the central chamber after an opponent attack during this experiment). Only these 195 behaviors, collectively termed as 'attacks', were therefore considered in the rest of the study. When 196 both females of a dyad stayed in the central chamber during the whole time of observation, the 197 winning female was determined as the one exhibiting oviposition behaviors.

Wasps were immediately frozen at $-20^{\circ} \mathrm{C}$ after the experiments, weighed using an electronic balance (Ohaus Discovery® model, accuracy: 0.01mg), and dissected to count the number of mature and non-mature eggs in their abdomen. Finally, after each contest, we counted the number of eggs 201 laid on the host by the winning female to determine their mature egg load before the contests (i.e., 202 initial mature egg load).

203 204 205

\subsection{Statistical analysis}

We performed data analyses with the software Rstudio (1.0.143 version - (C) 2009-2016 RStudio, Inc.), using $\alpha=0.05$. Our general approach was to use, when possible, parametric analyses in which the assumed distribution of residuals was matched to the data rather than transforming data to fit standard assumptions (Wilson and Hardy, 2002; Briffa et al., 2013). However, we used nonparametric tests when parametric conditions were not verified.

Experiment 1: We first investigated whether the mature egg load of females differed significantly between JHIII treatments, $4 \mathrm{~h}$ after injection, by performing a general linear model (GLM) assuming a Poisson distribution of errors. We then ran a linear model (LM) and a polynomial 
212 linear model (PLM) to explore the effect of JHIII treatments on the number of mature eggs 24h after

213 injection, and we compared the linear and polynomial models to determine which one provided a 214 better fit.

215 Experiment 2: We first verified that initial mature egg load did not differ between JHIII 216 females (mean egg load \pm S.E.: $6.2 \pm 0.7$ ) and control females (mean egg load \pm S.E.: $5 \pm 0.5$; 217 Student test: $\left.\mathrm{t}_{25}=-1.41, \mathrm{P}=0.16\right)$. We then performed a generalized linear mixed model (GLMM) with 218 a Poisson error distribution to explore the influence of contestants' initial mature egg load and 219 injection treatment on the number of attacks (calculated as the sum of chasing, hitting, and mounting 220 behaviors) displayed by females, with contest identity as a random factor. Lastly, we conducted a 221 GLMM assuming a binomial error distribution to explore the influence of initial mature egg load of 222 females and injection treatments on contest outcomes, with contest identity as a random factor. To 223 run this analysis, we defined contest outcome as a binary response: $0=$ the female lost and $1=$ the 224 female won.

\section{3. Results}

\subsection{Experiment 1: Effect of JH on female reproductive status}

The number of mature eggs in females did not vary across treatments $4 \mathrm{~h}$ after 228 injections (GLM: $\chi^{2}=0.006, \mathrm{df}=1, \mathrm{P}=0.94 ;$ Fig.2a). However, $24 \mathrm{~h}$ after injections, mature egg 229 load was influenced significantly by treatment ( $\left.L M: F_{1,86}=4.05, P=0.047, R^{2}=0.335\right)$. 230 Moreover, we found that the polynomial model fitted better than the linear model, with a dose-dependent effect of $\mathrm{JHIII}$ injection on egg maturation reaching a plateau at $64 \mathrm{pg} / \mu \mathrm{L}$ (PLM: $F_{1,85}=4.05, P=0.047, R^{2}=0.365 ;$ Fig.2b). 

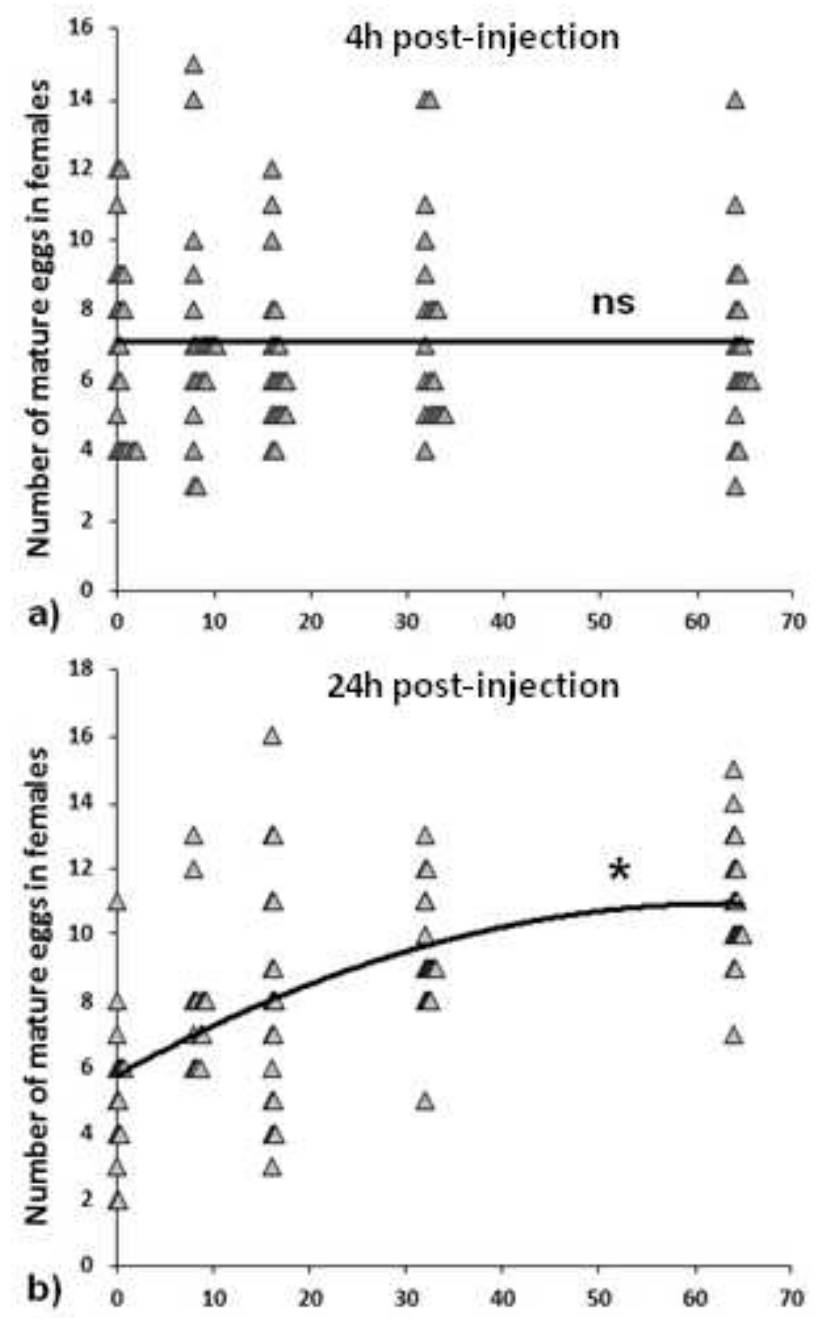

Dose of JHIII injected in females $(\mathrm{pg} / \mu \mathrm{L})$

234 Figure 2: Number of mature eggs of females injected with different doses of JHIII. a) $4 \mathrm{~h}$ after injections, b) $24 \mathrm{~h}$ after 235 injections. ns: non-significant; *: $\mathrm{P}<0.05$. Data points have been horizontally displaced from their binary positions to 236 show the numbers of observations.

\subsection{Experiment 2: Effect of JH on female aggressiveness and contests outcome}

The number of attacks displayed by females was influenced significantly by the 240 interaction between female egg load and injection treatment (Table 1). Wasps attacked 241 significantly more during a contest when they had more ready-to-lay eggs, and this effect 242 was stronger when females were injected with JHIII compared to control females injected 243 with acetone alone (Table 1, Fig. 3). Effect of female egg load x injection treatment interaction 
was still significant when removing data from the contest with a JHIII female displaying 22 attacks and her control opponent displaying 2 attacks (GLMM: $\chi^{2}=4.87, \mathrm{df}=1, \mathrm{P}=0.03$ ).

Table 1. Effect of initial egg load difference and injection on female agonistic behaviors.

\begin{tabular}{lccc}
\hline Factors affecting female aggressiveness & df & $\chi^{\mathbf{2}}$ & $\mathbf{P}$ \\
\hline Egg load & 1 & 4.81 & $<\mathbf{0 . 0 5}$ \\
Injection & 1 & 20.34 & $<\mathbf{0 . 0 0 1}$ \\
Egg load x Injection & 1 & 7.09 & $\mathbf{0 . 0 0 8}$ \\
\hline
\end{tabular}

$P$-values of significant explanatory variables are shown in bold font

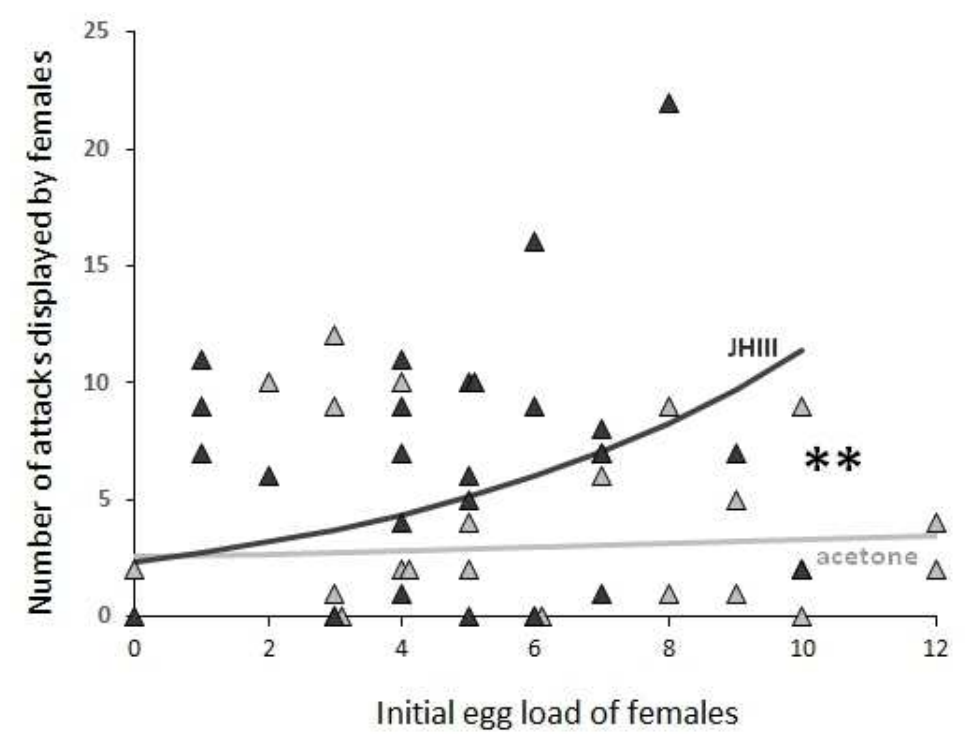

250 Figure 3. a) Number of attacks displayed by females treated with acetone alone (light data points, light gray line; N=25) 251 or with JHIII (dark data points, dark curve; $\mathrm{N}=25$ ) when fighting for a $4^{\text {th }}$ instar larva of C. maculatus. **: $\mathrm{P}<0.01$. Data points have been horizontally displaced from their binary positions to show the numbers of observations. Statistical analyses showed that effect of 'Egg load $\mathrm{x}$ Injection' interaction was still significant when removing data from the contest with a JHIII female displaying 22 attacks and her control opponent displaying 2 attacks (GLMM: $\chi^{2}=4.87$, df=1, $255 \mathrm{P}=0.03)$. 
259 injection alone (Table 2). However, females had higher probabilities of winning contest 260 when they had more ready-to-lay-eggs before contests (Table 2, Fig. 4).

262 Table 2. Effect of initial egg load and injection on the winning probability of females.

\begin{tabular}{lccc}
\hline Factors affecting contest outcomes & df & $\chi^{2}$ & $\mathbf{P}$ \\
\hline Egg load & 1 & 4.62 & $\mathbf{0 . 0 3}$ \\
Injection & 1 & 0.54 & 0.46 \\
Egg load x Injection & 1 & 0.22 & 0.64 \\
\hline$P$-values of significant explanatory variables are shown in bold font
\end{tabular}

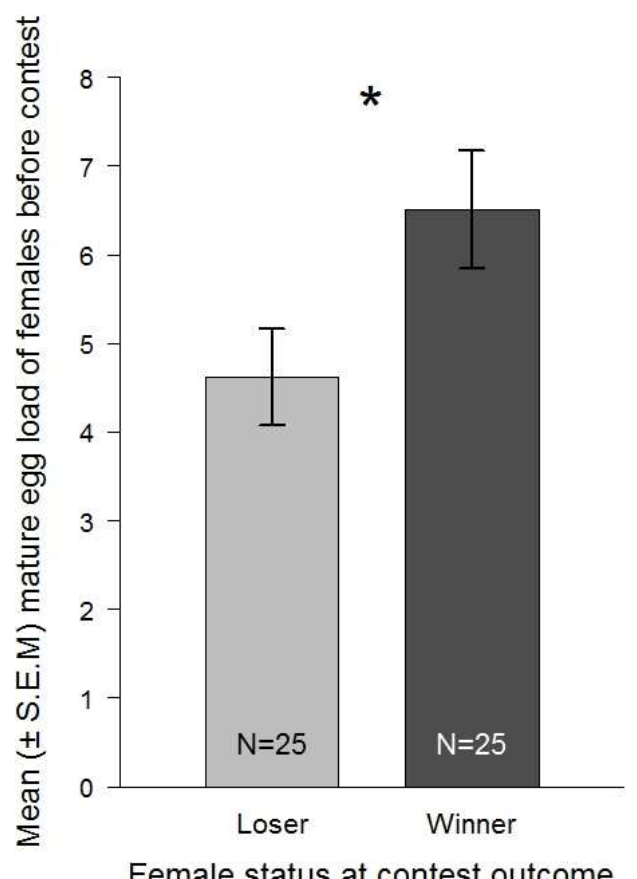

265 Figure 4. Mean $( \pm$ S.E.M) number of mature eggs in females before the contest (i.e. initial egg load) and their winning 266 status at contest outcome. *: P < 0.05. Sample sizes are shown as text within each histogram bar.

\section{Discussion}

The purpose of our study was to test the effect of $\mathrm{JH}$ manipulation on female reproductive status, aggressiveness and conflict resolution in the solitary ectoparasitoid $E$. 
vuilleti. By measuring how JHIII injections affect oocyte maturation, we showed that JHIII

272 did not influence mature egg load after $4 \mathrm{~h}$, but had a dose-dependent gonadotropic effect in 273 females $24 \mathrm{~h}$ post-injection. Moreover, JHIII injections and egg load interacted to affect 274 female aggressiveness during competition for host access.

\subsection{Effect of JH on females' reproductive status}

In our first experiment, the reproductive status of the wasps varied after $24 \mathrm{~h}$ according to the amount of JHIII injected in females: wasps injected with JHIII had more ready-to-lay eggs than those injected only with acetone. This result therefore suggests that $\mathrm{JH}$ has a gonadotropic effect in $E$. vuilleti females, and was expected given that $\mathrm{JH}$ plays an important and diverse role in adult reproduction of many insect species by regulating vitellogenesis in the fat body and vitellogenin uptake by the ovaries (reviewed by Tobe and Stay, 1985; Nijhout, 1994; Robinson and Vargo, 1997; Hartfelder, 2000). In Hymenoptera, JH is involved in the regulation of ovarian development in the facultatively eusocial sweat bee Megalopta genalis (Smith et al., 2013), primitively social polistine wasps (Barth et al., 1975), halictine bees (Bell, 1973) and bumblebees (Bloch et al. 2000), but not in the highly social honeybee Apis mellifera (reviewed in Robinson, 1992; Robinson and Vargo, 1997).

Because egg maturation was affected by $\mathrm{JH}$ in a dose-dependent way, we can reject the hypothesis that the physiological response to injection was an artefact related to activation of another signaling pathway such as the stress response. Finally, we found no difference in mature egg load between control and JHIII treated females $4 \mathrm{~h}$ after injections. This is consistent with what we found in the second experiment, where contestants had the same number of mature eggs before contests, whether they were injected with JHIII or with vehicle alone. Our results therefore suggest that the egg maturation response to $\mathrm{JH}$ injection may happen only after $4 \mathrm{~h}$ post-injection. Decoupling the effect of ovarian maturation and $\mathrm{JH}$ treatment on aggressive interactions is sometimes difficult (see Barth et 
injection permitted us to disentangle the effects of JHIII and mature egg load on aggressiveness and contest outcomes.

\subsection{Effect of JH and Subjective Resource Value on female competition}

In our second experiment, we investigated the role of $\mathrm{JH}$ injection and mature egg load on female aggressiveness and contest outcome. Our results support the idea that reproductive state influences behavioral decisions during fights (Neat et al., 1998; Stokkebo and

Hardy, 2000; Arnott and Elwood, 2008). As previously demonstrated in E. vuilleti (Mohamad et al., 2010; Mathiron et al., 2018), we found that more gravid females (i.e., females with more mature eggs) displayed more attacks and had a higher probability of winning contests. This is also consistent with game theoretical predictions that contest outcome is influenced by differences in the value that opponents place in the resource ('Subjective Resource Value', SRV; Maynard-Smith and Parker, 1976; Hammerstein, 1981; Enquist and Leimar, 1987). For instance, parasitoid females with

higher probability of winning contests (Stokkebo and Hardy, 2000; Brown et al., 2006, 2007; are more prepared to oviposit and should therefore be more motivated to fight and have a Dissanayake et al., 2009). We therefore added evidence that the initial egg load as a component of SRV plays a main role in conflict resolution in E. vuilleti.

More interestingly, we found an interaction between JHIII injection and mature egg load on the number of aggressive behaviors displayed by females. We observed that the effect of initial egg load on aggressiveness was more pronounced when contestants were injected with JHIII. We therefore suggest that JHIII promoted female aggressiveness during fights for host access. This agrees with previous studies exploring the role of $\mathrm{JH}$ on agonistic behaviors in insects (Tibbetts and Crocker, 2014). Topical application of methoprene (a JH analog) induced strong reactions to confrontation (i.e., aggression/flight behavior) in individuals of Schistocerca gregaria and Locusta migratoria (Wiesel et al., 1996). Scott (2006) made the same observation in Nicrophorus orbicollis 
and Nicrophorus tomentosus: methoprene application significantly increased the number of injuries

321 from aggressive interactions in males and females in the absence of a resource. Moreover, in the cockroach Nauphoeta cinerea, JHIII injections sustain males' aggressive posture during intra-sexual

323 fights (Kou et al., 2008). Here, we highlight that JH treatment upregulated aggressive behaviors convergence of endocrine effects across vertebrates and insects (Tibbetts and Crocker, 2014).

\subsection{Evolution of JH functions across hymenopterans with different degrees of sociality}

$\mathrm{JH}$ has been observed to play two important roles in life history regulation in hymenopteran societies: gonadotropin and behavioral pacemaker (Robinson and Vargo, 1997). Because regulation of reproduction is generally the main role of $\mathrm{JH}$ in adult insects (Nijhout, 1994), it is assumed that this was an ancestral function of this hormone in social hymenoptera. So, how the relationship between $\mathrm{JH}$ regulation of reproduction and $\mathrm{JH}$ regulation of aggressiveness has evolved across hymenopteran taxa with different degree of sociality remains an open question. Currently, two hypotheses have been advanced: i) the 'novel- or single-function hypothesis' (Robinson et al., 1992, Robinson and Vargo, 1997; Agraharia and Gadagkar, 2003) proposes that the role of JH has changed 337 from an exclusively reproductive function in primitively eusocial species (those lacking morphologically distinct queen and worker castes), to an exclusively behavioral function in highly eusocial societies (those containing morphologically distinct castes), whereas ii) the 'split-function hypothesis' (West-Eberhard, 1996) proposes that JH affects regulation of both reproduction and behavior in ancestral non-social species, but that these different effects of $\mathrm{JH}$ were then divided between queens and workers in more social species (i.e. regulation of reproductive maturation in egg-laying queens and behavioral pacemaker in workers). Previous studies have lent some support to both hypotheses (Agraharia and Gadagkar, 2003; Giray et al., 2005). To the extent that JH modulates 
ovarian development and aggressiveness in E. vuilleti, a strict non-social hymenopteran, our work 346 supports the split-function hypothesis, but further investigations in non-social hymenopteran species 347 will be essential for comparative studies on the evolution of $\mathrm{JH}$ function.

\section{Conclusion}

By testing the role of $\mathrm{JH}$ on both reproductive status and aggressiveness in female E. vuilleti, we have shown for the first time in a non-social hymenopteran parasitoid that JH has a gonadotropic effect and promotes aggressive behaviors during contests over hosts. Because JH upregulates aggressive behaviors associated with reproduction, our data support the possibility that $\mathrm{JH}$ in insects and testosterone in vertebrates have parallel functions, suggesting evolutionary convergence of endocrine systems.

\section{Founding}

Acknowledgement technical assistance. We thank Dr. Mark Sheridan and 2 anonymous reviewers for helpful comments on the manuscript.

Adkins-Regan, E., 2005. Hormones and Animal Social Behavior, The Journal of Nervous and Mental Disease. 
in the primitively eusocial wasp, Ropalidia marginata. J. Insect Physiol. 49, 217-222. https://doi.org/10.1016/S0022-1910(02)00268-8

Amsalem, E., Teal, P., Grozinger, C.M., Hefetz, A., 2014. Precocene-I inhibits juvenile hormone biosynthesis, ovarian activation, aggression and alters sterility signal production in bumble bee (Bombus terrestris) workers. J. Exp. Biol. 217, 3178-3185. https://doi.org/10.1242/jeb.107250

Arnott, G., Elwood, R.W., 2008. Information gathering and decision making about resource value in animal contests. Anim. Behav. https://doi.org/10.1016/j.anbehav.2008.04.019

Barth, R.H., Lester, L.J., Sroka, P., Kessler, T., Hearn, R., 1975. Juvenile hormone promotes dominance behavior and ovarian development in social wasps (Polistes annularis). Experientia 31, 691-692. https://doi.org/10.1007/BF01944632

Barton, R.A., 1993. Sociospatial mechanisms of feeding competition in female olive baboons, Papio anubis. Anim. Behav. 46, 791-802.

Bell, W.J., 1973. Factors controlling initiation of vitellogenesis in a primitively social bee, Lasioglossum zephyrum (Hymenoptera: Halictidae). Insectes Soc. 20, 253-260. https://doi.org/10.1007/BF02223194

Bloch, G., Borst, D.W., Huang, Z., Robinson, G.E., Cnaani, J., Hefetz, A., 2000. Juvenile hormone titers, juvenile hormone biosynthesis, ovarian development and social environment in Bombus terrestris. J. Insect Physiol. 46, 4757.

Breed, M.D., Bell, W.J., 1983. Hormonal influences on invertebrate aggressive behavior, in: Svare, B.B. (Ed.), Hormones and Aggressive Behavior. Plenum Press, New York, NY, pp. 577-590.

Brent, C., Peeters, C., Dietmann, V., Crewe, R., Vargo, E., 2006. Hormonal correlates of reproductive status in the queenless ponerine ant, Streblognathus peetersi. J. Comp. Physiol. A Neuroethol. Sensory, Neural, Behav. Physiol. 192, 315-320. https://doi.org/10.1007/s00359-005-0065-6

Briffa, M., Hardy, I.C.W., Gammell, M.P., Jennings, D.J., Clarke, D.D., Goubault, M., 2013. Analysis of animal contest data, in: Hardy, I.C.W., Briffa, M. (Eds.), Animal Contests. Cambridge University Press, pp. 47-85.

Brown, W.D., Chimenti, A.J., Siebert, J.R., 2007. The payoff of fighting in house crickets: Motivational asymmetry increases male aggression and mating success. Ethology 113, 457-465. https://doi.org/10.1111/j.14390310.2007.01357.x

Brown, W.D., Smith, A.T., Moskalik, B., Gabriel, J., 2006. Aggressive contests in house crickets: size, motivation and the information content of aggressive songs. Anim. Behav. 72, 225-233. https://doi.org/10.1016/j.anbehav.2006.01.012 
Buck, C.L., Barnes, B.M., 2003. Androgen in free-living arctic ground squirrels: Seasonal changes and influence of staged male-male aggressive encounters. Horm. Behav. 43, 318-326. https://doi.org/10.1016/S0018506X(02)00050-8

Chase, I.D., 1974. Models of hierarchy formation in animals societies. Behav. Sci. 19, 374-382.

403 Collias, N.E., 1944. Aggressive behavior among vertebrate animals. Physiol. Zool. 17, 83-123.

Damiens, D., Imbert, E., Bressac, C., Thibeaudeau, C., Chevrier, C., 2001. Egg-laying, pre-imaginal growth dynamics, and mortality in Eupelmus orientalis and Dinarmus basalis, two solitary ectoparasitoids of Callosobruchus maculatus. Entomol. Exp. Appl. 99, 97-105. https://doi.org/10.1023/A:1018954320519

Díaz-Uriarte, R., 1999. Anti-predator behaviour changes following an aggressive encounter in the lizard Tropidurus hispidus. Proc. R. Soc. B Biol. Sci. 266, 2457-2464. https://doi.org/10.1098/rspb.1999.0946

Dissanayake, A., Galloway, T.S., Jones, M.B., 2009. Physiological condition and intraspecific agonistic behaviour in Carcinus maenas (Crustacea: Decapoda). J. Exp. Mar. Bio. Ecol. 375, 57-63. https://doi.org/10.1016/j.jembe.2009.05.007

Emlen, D.J., Nijhout, H.F., 2000. The Development and Evolution of Exaggerated Morphologies in Insects. Annu. Rev. Entomol. 45, 661-708. https://doi.org/10.1146/annurev.ecolsys.36.102003.152640

Enquist, M., Leimar, O., 1987. Evolution of fighting behaviour: The effect of variation in resource value. J. Theor. Biol. 127, 187-205. https://doi.org/10.1016/S0022-5193(87)80130-3

Festa-Bianchet, M., Apollonio, M., Mari, F., Rasola, G., 1990. Aggression among Lekking Male Fallow Deer (Dama dama): Territory Effects and Relationship with Copulatory Success. Ethology. 85, 236-246.

Field, S.A., Calbert, G., 1999. Don't count your eggs before they're parasitized: contest resolution and the trade-offs during patch defense in a parasitoid wasp. Behav. Ecol. 10, 122-127. https://doi.org/10.1093/beheco/10.2.122

Gauthier, N., Monge, J.P., 1999. Could the egg itself be the source of the oviposition deterrent marker in the ectoparasitoid Dinarmus basalis? J. Insect Physiol. 45, 393-400. https://doi.org/10.1016/S0022-1910(98)00138-3

Giray, T., Giovanetti, M., West-Eberhard, M.J., 2005. Juvenile hormone, reproduction, and worker behavior in the neotropical social wasp Polistes canadensis. Proc. Natl. Acad. Sci. 102, 3330-3335. https://doi.org/10.1073/pnas.0409560102

Goubault, M., Cortesero, A. M., Poinsot, D., Wajnberg, E., Boivin, G., 2007. Does host value influence female aggressiveness, contest outcome and fitness gain in parasitoids? Ethology, 113(4), 334-343. https://doi.org/10.1111/j.1439-0310.2006.01325.x 
Hammerstein, P., 1981. The role of asymmetries in animal contests. Anim. Behav. 29, 193-205. https://doi.org/10.1016/S0003-3472(81)80166-2

Hardy, I.C.W., Briffa, M., 2013. Animal contests. Cambridge University Press.

Hartfelder, K., 2000. Insect juvenile hormone: from "status quo" to high society. Brazilian J. Med. Biol. Res. 33, 157-77. https://doi.org/10.1590/S0100-879X2000000200003

Hirschenhauser, K., Oliveira, R.F., 2006. Social modulation of androgens in male vertebrates: Meta-analyses of the challenge hypothesis. Anim. Behav. 71, 265-277. https://doi.org/10.1016/j.anbehav.2005.04.014

Hirschenhauser, K., Winkler, H., Oliveira, R.F., 2003. Comparative analysis of male androgen responsiveness to social environment in birds: The effects of mating system and paternal incubation. Horm. Behav. 43(4), 508-519. https://doi.org/10.1016/S0018-506X(03)00027-8

Hughes, J. P., Harvey, I. F., Hubbard, S. F., 1994. Host-searching behavior of Venturia canescens (Grav.) (Hymenoptera: Ichneumonidae): Interference-the effect of mature egg load and prior behavior. J. Insect Behav. 7(4), 433-454. https://doi.org/10.1007/BF02025442

Innocent, T.M., West, S.A., Sanderson, J.L., Hyrkkanen, N., Reece, S.E., 2011. Lethal combat over limited resources: Testing the importance of competitors and kin. Behav. Ecol. 22, 923-931. https://doi.org/10.1093/beheco/arq209

Jakobsson, S., Brick, O., Kullberg, C., 1995. Escalated fighting behaviour incurs increased predation risk. Anim. Behav. 49, 235-239. https://doi.org/10.1016/0003-3472(95)80172-3

Jaloux, B., Sanon, A., Huignard, J., Monge, J.P., 2004. Interspecific relationships between the solitary ectoparasitoid, Eupelmus vuilleti (Crw.) (Eupelmidae), and its sympatric species, Dinarmus basalis (Rond.) (Pteromalidae), in the presence of their host, Callosobruchus maculatus pic (Coleoptera Bruchidae). J. Insect Behav. 17, 793-808. https://doi.org/10.1023/B:JOIR.0000048989.36181.4d

Kelstrup, H.C., Hartfelder, K., Esterhuizen, N., Wossler, T.C., 2017. Juvenile hormone titers, ovarian status and epicuticular hydrocarbons in gynes and workers of the paper wasp Belonogaster longitarsus. J. Insect Physiol. 98, 83-92. https://doi.org/10.1016/j.jinsphys.2016.11.014

Kelstrup, H.C., Hartfelder, K., Nascimento, F.S., Riddiford, L.M., 2014a. Reproductive status, endocrine physiology and chemical signaling in the Neotropical, swarm-founding eusocial wasp Polybia micans. J. Exp. Biol. 217, 23992410. https://doi.org/10.1242/jeb.096750

Kelstrup, H.C., Hartfelder, K., Nascimento, F.S., Riddiford, L.M., 2014b. The role of juvenile hormone in dominance behavior, reproduction and cuticular pheromone signaling in the caste-flexible epiponine wasp, Synoeca surinama. Front. Zool. 11, 1-19. https://doi.org/10.1186/s12983-014-0078-5 
Kelstrup, H.C., Hartfelder, K., Wossler, T.C., 2015. Polistes smithii vs. Polistes dominula: the contrasting endocrinology and epicuticular signaling of sympatric paper wasps in the field. Behav. Ecol. Sociobiol. 69, 2043-2058. https://doi.org/10.1007/s00265-015-2015-9

Klukowski, M., Nelson, C.E., 1998. The challenge hypothesis and seasonal changes in aggression and steroids in male

undulatus hyacinthinus). Horm. Behav. 33, 197-204. https://doi.org/10.1006/hbeh.1998.1449

Kou, R., Chou, S.Y., Huang, Z.Y., Yang, R.L., 2008. Juvenile hormone levels are increased in winners of cockroach fights. Horm. Behav. 54, 521-527. https://doi.org/10.1016/j.yhbeh.2008.05.011

Lynch, J.W., Ziegler, T.E., Strier, K.B., 2002. Individual and seasonal variation in fecal testosterone and cortisol levels of wild male tufted capuchin monkeys, Cebus apella nigritus. Horm. Behav. 41, $275-287$. https://doi.org/10.1006/hbeh.2002.1772

Mathiron, A.G.E., Pottier, P., Goubault, M., 2018. Let the most motivated win : resource value components affect contest outcome in a parasitoid wasp. Behav. Ecol. 00, 1-8. https://doi.org/10.1093/beheco/ary084

Maynard-Smith, J., Parker, G.A., 1976. The logic of asymmetric animal contests. Anim. Behav. 24, 159-175.

Maynard-Smith, J., Price, G. R., 1973. The logic of animal conflict. Nature, 246, 15-18. https://doi.org/10.1038/246015a0

Mohamad, R., Monge, J.P., Goubault, M., 2013. Do resource value and ownership status affect intensity and resolution of contests in a parasitoid wasp? Entomol. Exp. Appl. 147, 99-109. https://doi.org/10.1111/eea.12049

Mohamad, R., Monge, J.P., Goubault, M., 2012. Wait or fight? Ownership asymmetry affects contest behaviors in a parasitoid wasp. Behav. Ecol. 23, 1330-1337. https://doi.org/10.1093/beheco/ars125

Mohamad, R., Monge, J.P., Goubault, M., 2010. Can subjective resource value affect aggressiveness and contest outcome in parasitoid wasps? Anim. Behav. 80, 629-636. https://doi.org/10.1016/j.anbehav.2010.06.022

Moore, M.C., 1986. Elevated testosterone levels during nonbreeding-season territoriality in a fall-breeding lizard, Sceloporus jarrovi. J. Comp. Physiol. A 158, 159-163. https://doi.org/10.1007/BF01338559

Muller, M.N., Wrangham, R.W., 2004. Dominance, aggression and testosterone in wild chimpanzees: A test of the “challenge hypothesis.” Anim. Behav. 67, 113-123. https://doi.org/10.1016/j.anbehav.2003.03.013

Neat, F., Huntingford, F., Beveridge, M., 1998. Fighting and assessment in male cichlid fish: the effects of asymmetries in gonadal state and body size. Anim. Behav. 55, 883-91. https://doi.org/10.1006/anbe.1997.0669

Nijhout, H.F., 1994. Insect Hormones. Princeton University Press, Princeton.

Oliveira, R.F., Hirschenhauser, K., Carneiro, L.A., Canario, A.V.M., 2002. Social modulation of androgen levels in male 

4959(01)00523-1

Palombit, R.A., 1993. Lethal territorial aggression in a white-handed gibbon. Am. J. Primatol. 31, 311-318. https://doi.org/10.1002/ajp.1350310407

Pearce, A.N., Huang, Z.Y., Breed, M.D., 2001. Juvenile hormone and aggression in honey bees. J. Insect Physiol. 47, 1243-1247. https://doi.org/10.1016/S0022-1910(01)00109-3

Petersen, G., Hardy, I.C.W., 1996. The importance of being larger: parasitoid intruder - owner contests and their implications for clutch size. Anim. Behav. 51, 1363-1373. https://doi.org/10.1006/anbe.1996.0139

Ramaseshadri, P., Farkaš, R., Palli, S.R., 2012. Recent Progress in Juvenile Hormone Analogs (JHA) Research, 1st ed, Advances in Insect Physiology. Elsevier Ltd. https://doi.org/10.1016/B978-0-12-391500-9.00005-X

Robinson, G.E., 1992. Regulation of Division of Labor in Insect Societies. Annu. Rev. Entomol. 37, 637-665. https://doi.org/10.1146/annurev.en.37.010192.003225

Robinson, G.E., Vargo, E.L., 1997. Juvenile hormone in adult eusocial hymenoptera: Gonadotropin and behavioral pacemaker. Arch. Insect Biochem. Physiol. 35, 559-583. https://doi.org/10.1002/(SICI)15206327(1997)35:4<559::AID-ARCH13>3.0.CO;2-9

Röseler, P.F., 1991. Reproductive competition during colony establishment, in: Ross, K.G., Matthews, R.W. (Eds.), The Social Biology of Wasps. Cornell University Press., Ithaca, NY, pp. 309-335.

Röseler, P.F., Röseler, I., Strambi, A., Augier, R., 1984. Influence of insect hormones on the establishment of dominance hierarchies among foundresses of the paper wasp, Polistes gallicus. Behav. Ecol. Sociobiol. 15, 133-142. https://doi.org/10.1007/BF00299381

Röseler, P.F., Röseler, I., Strambi, A., 1980. The Activity of Corpora Allata in Dominant and Subordinated Females of the Wasp Polistes Gallicus. Insectes Soc. 27, 97-107.

Rowland, W.J., 1989. The effects of body size, aggression and nuptial coloration on competition for territories in male threespine sticklebacks, Gasterosteus aculeatus. Anim. Behav. 37, 282-289. https://doi.org/10.1016/00033472(89)90117-6

Salvador, A., Veiga, J.P., Martin, J., Lopez, P., Abelenda, M., Puerta, M., 1996. The cost of producing a sexual signal: Testosterone increases the susceptibility of male lizards to ectoparasitic infestation. Behav. Ecol. 7, 145-150. https://doi.org/10.1093/beheco/7.2.145 
Sasagawa, H., Sasaki, M., Okada, I., 1989. Hormonal Control of the Division of Labor in Adult Honeybees (Apis mellijlera L.) I. Effect of Methoprene on Corpora Allata and Hypopharyngeal Gland, and Its cr-Glucosidase Activity. Japanese Soc. Appl. Entomol. Zool. 24, 66-77.

Schwagmeyer, P.L., Woontner, S.J., 1985. Mating Competition in an Asocial Ground-Squirrel, Spermophilus tridecemlineatus. Behav. Ecol. Sociobiol. 17, 291-296. https://doi.org/10.1007/BF00300149

Scott, M.P., 2006. The role of juvenile hormone in competition and cooperation by burying beetles. J. Insect Physiol. 52, 1005-1011. https://doi.org/10.1016/j.jinsphys.2006.04.006

Simmons, L., 1986. Intermale Competition and Mating Success in the Field Cricket, Gryllus bimaculatus (Degeer). Anim. Behav. 34, 567-579. https://doi.org/10.1016/S0003-3472(86)80126-9

Sláma, K., 1971. Insect juvenile hormone analogues. Annu. Rev. Biochem. 40, 1079-102. https://doi.org/10.1146/annurev.bi.40.070171.005243

Smith, A.R., Kapheim, K.M., Pérez-Ortega, B., Brent, C.S. \& Wcislo, W.T. 2013. Juvenile hormone levels reflect social opportunities in the facultatively eusocial sweat bee Megalopta genalis (Hymenoptera : Halictidae). Horm. Behav. $63,1-4$.

Smith, J.M., Price, G.R., 1973. The logic of animal conflict. Nature 246, 15-18. https://doi.org/10.1038/246015a0

Stokkebo, S., Hardy, I.C.W., 2000. The importance of being gravid: egg load and contest outcome in a parasitoid wasp. Anim. Behav. 59, 1111-1118. https://doi.org/10.1006/anbe.2000.1407

Terrasse, P.C., Rojas-Rousse, D., 1986. Distribution de la ponte et évitement du superparasitisme chez l'hyménoptère solitaire Bruchocida vuilleti Cwf. (Hym., Eupelmidae), parasite des stades larvaires de son hôte, Callosobruchus maculatus F. (Col., Bruchidae). J. Appl. Entomol. 101, 243-256. https://doi.org/10.1111/j.14390418.1986.tb00855.x

Tibbetts, E.A., Crocker, K.C., 2014. The challenge hypothesis across taxa: Social modulation of hormone titres in vertebrates and insects. Anim. Behav. 92, 281-290. https://doi.org/10.1016/j.anbehav.2014.02.015

Tibbetts, E.A., Huang, Z.Y., 2010. The Challenge Hypothesis in an Insect: Juvenile Hormone Increases during Reproductive Conflict following Queen Loss in Polistes Wasps. Am. Nat. 176, $123-130$. https://doi.org/10.1086/653664

Tibbetts, E.A., Izzo, A.S., 2009. Hormones and Behavior Endocrine mediated phenotypic plasticity: Conditiondependent effects of juvenile hormone on dominance and fertility of wasp queens. Horm. Behav. 56, 527-531. https://doi.org/10.1016/j.yhbeh.2009.09.003

Tibbetts, E.A., Vernier, C., Jinn, J., 2013. Juvenile hormone influences precontest assessment behaviour in Polistes 
Tobe, S.S., Stay, B., 1985. Structure and Regulation of the Corpus Allatum. Adv. In Insect Phys. 18, 305-432. https://doi.org/10.1016/S0065-2806(08)60043-0

Vogel, E.R., 2005. Rank differences in energy intake rates in white-faced capuchin monkeys, Cebus capucinus: The effects of contest competition. Behav. Ecol. Sociobiol. 58, 333-344. https://doi.org/10.1007/s00265-005-0960-4

West-Eberhard, M., 1996. Wasp societies as microcosms for the study of development and evolution, in: Turillazzi, S., West-Eberhard, M. (Eds.), Natural History and Evolution of Paper Wasps. Oxford University Press, Oxford, pp. $290-31$.

West-Eberhard, M.J., 1979. Sexual Selection, Social Competition, and Evolution. Proc. Amercian Philos. Soc. 123, 222234.

Wheeler, D., 1996. The Role of Nourishment in Oogenesis. Annu. Rev. Entomol. 41, 407-431. https://doi.org/10.1146/annurev.ento.41.1.407

Wiesel, G., Tappermann, S., Dorn, A., 1996. Effects of Juvenile Hormone and Juvenile Hormone Analogues on the Phase Behaviour of Schistocerca gregaria and Locusta migratoria. J. Insect Physiol. 42, 385-395.

Wilson, K., Hardy, I.C.W., 2002. Statistical analysis of sex ratios: an introduction, in: Hardy, I.C.W. (Ed.), Sex Ratios: Concepts and Research Methods. Part 2. Statistical Analysis of Sex Ratio Data. Cambridge University Press, New York, pp. 46-92.

Wingfield, J.C., 1984. Androgens and Mating Systems: Testosterone-Induced Polygyny in Normally Monogamous Birds. Auk 101, 665-671. https://doi.org/10.2307/4086893

Wingfield, J.C., Hegner, R.E., Dufty, A.M., Ball, G.F., 1990. The "Challenge Hypothesis": Theoretical Implications for Patterns of Testosterone Secretion, Mating Systems, and Breeding Strategies. Am. Nat. 136, 829-846. https://doi.org/10.1086/285134

Zera, A.J., 2007. Endocrine analysis in evolutionary-developmental studies of insect polymorphism: Hormone manipulation versus direct measurement of hormonal regulators. Evol. Dev. 9, 499-513. https://doi.org/10.1111/j.1525-142X.2007.00181.x 